\title{
The Study of the Model of Intelligent Community Building
}

\author{
Yucong Zhang \\ Public Administration and Law School, Southwest Jiaotong University, Chengdu, China \\ aronghefan@163.com
}

Keywords: Intelligent community; Model study; The Top-down Model; The Bottom-up Model

\begin{abstract}
The economic society has got a further development and the Internet, Internet of things and other technology has got great progress. Serving for the public through intelligent community buliding and intelligent approaches has become the consensus of the governments of all levels. This paper analyzes the intelligent community building with the methods of literature, field investigation and contrastive analysis. Based on existing research and the research and study of Chengdu's intelligent community, this paper makes a comparative analysis to the model of intelligent community. We have done studies on connotation, specific operational details and the comparative analysis of the models it will be great development for the intelligent community if the different building models and developing approaches can be united to some degree and form the coordinated scheme of intelligent community building. So the main purpose of this paper is expected to give some advice for the future building of intelligent community.
\end{abstract}

\section{Introduction}

The conception of the intelligent community stems from Western countries [1]. The related study of intelligent community was started from 2010. The study has dealt with the following situations, such as the related definition, the domestic and international current situation, the deficiency of building, the solution of core problem, the effect of different elements and the models at home and abroad.

Through the cnki.net, the author discovered that the literature about the intelligent community was first published in 2010. As of March 2016 there are 48 core journals published with the "intelligent community" as the keywords. These articles in a large part of the research focused on the technical research of the intelligent community building [2] [3]. As for the relation of intelligent city and intelligent community, most of the scholars regard the intelligent community as the part of intelligent city [4] [5]. A few literature about the model of intelligent community building is focused some certain and specific cases [6], but there is not a literature is about the summary. Based on the existed research and the study about the Chengdu's intelligent community pilot, this paper is trying to refine and summarize the existing model of intelligent community.

\section{The Top-down Model of Intelligent Community Development}

The Connotation of the "Top-down" Mode of Intelligent Community. Under the top-down model of intelligent community building, the building of intelligent community has a united guidance from the proposition, the construction of planning standards, infrastructure, and building of supporting platform. Led by the government, it makes the city (district) levels of government main body for the construction, use the modern information technology to coordinate public administration, public services and business services and other resources, is supported by cross-sectoral and cross-level integrated information service platform, relying on moderate leading infrastructure construction, promote the intelligence of public service and convenience .In the operation, this top-down intelligence community building model can be divided into two kinds: intelligent community building with the building of intelligent city as the core and the separate building of intelligent community.

Specific Operational Details of the "Top-down" Intelligent Community Building. In the operation, this top-down intelligence community building model can be divided into two kinds. 
The intelligent community building under the intelligent city pilot: With the development of the intelligent city, the building of intelligent community, as the best layout points of intelligent city, are also widely carried out [7]. Intelligent community construction under the guidance of the intelligent city is a pilot for intelligent city. The building of intelligent community is a breakthrough for the coordinateted building of intelligent city. It lead the conception of intelligent city onto the community level and makes intelligent community pilot in the building of intelligent city. It form the overall planning and development priorities about government formation, use the big data and platform of the government, make informatization as its methods, solve people's livelihood and improve city governance through optimizing infrastructure.

Independently intelligent community building:The proposition of building, formulation of planning standards, the construction of infrastructure, the building of supporting platform of the pilot is relatively independent. In the building of intelligent community, the government of city (district) pay more attention to Top-level design, Unified planning and the development of relevant norms.

Under the united planning, the existing data and resources of the region is integrated, the original community platform is incorporated, the service platform of informatization is constructed and the right of using of platform is transferred to the lower levels on the basis of information safety [8]. The government of city (district) is responsible for the city management platform; the streets (community) use the internet to complete tasks that the higher levels send to and release government, public services information; social subjects, community residents use platform to handle the business and feedback opinions.

The Evaluation for the Model of Top-down Intelligent Community. Either in the building of intelligent community with the conception of city or the building of intelligent community relatively dependent, the model of Top-down ensures the government as the leader. Viewed from the system and the whole situation, the government set plans for the intelligent community. The governments build a system of information collection and data security through the improvement of infrastructure from the levels of feeling, internet, facility, which makes sure that the huge information and data can function safely. The separation between different departments is broken through the cooperation, which realized the optimization of inner construction and avoids the separated department, the separated building and data separation. The affairs related communities and residents in different departments will be united; a united and integrated information platform will be built. Resources will be saved in order to avoid the repeated building. The direct interaction between the government and residents will be ensured.

It is very hard to realize the complete unity for online, offline and in and out of region, because the limited resources and people of the government and it are difficult to evaluate and check the information coming into the platform. This kind of model focuses on unity and the safety of information, but it usually regardless the realistic need and the residents' feeling. The creativity of community and social organizations cannot be fully used.

\section{The Bottom-up Model of Intelligent Community Development}

The Connotation of the Bottom-up Model of Intelligent Community. Bottom-up intelligent community building mode takes streets (community) or social organizations, such as non-profit organizations, commercial enterprises as the main body, makes the implement of community-government services, convenience services and social services as the goal. Based on the existed and integrated resources, it develops the information service platform to provide community-government services, convenience services and social services and other terminal equipment providing security access control, intelligent monitoring and wisdom pension.

Street (community) will take residents' feelings, needs, participation and involvement ability into the path of intelligence, in order to achieve maximum grassroots autonomy and the convenience of public service through determining the construction path independently. [9] 
Specific Operational Details of the Bottom-up Intelligent Community Building. Based on core role of different construction subjects,specific operational details of the bottom-up intelligent community buliding is usually thought to be of two kinds[10].

One way is led by the street (Community Council), relying on community comprehensive management resources to build community information platform or to merge existing systems to generate "intelligent community" system. Grassroots employees realize the data collection and community management through the system; residents and social organizations can realize information inquiry and online check-government; social subjects make interactions through the platform.

The other way is to solve the problem of a particular aspect of the community. Under the government policy, non-profit organizations, commercial enterprises develop services for community residents. Through the development of fixed-mobile terminals, the interactive equipment is applied in the wisdom of old age and wisdom medical. It is available to users of medical emergency, life support and active care and other services.

The Evaluation for the Model of Bottom-up Intelligent Community. The building of intelligent community led by community or other social subject's proceeds from the realistic situation of the community or the need of residents and combines the community building with the needs of the residents. The community integrates the existing resources. It builds applications combined with the needs of residents, secures grassroots participate the intelligent community building, gives full play to the autonomy and innovativeness of the grass-roots organizations. Non-profit organizations and commercial enterprises can use their advanced technology and abundant capital and participate in the intelligent community. They can help the community to solve the lacking of capital and technology, and realize the diversity of public services, community-government services and convenience services through different ways.

This mode builds street of the intelligent community, formulates the plan and carries out the building independently. On the one hand, it brings too much burden for the grass-root communities; on the other hand, it may cause the polarization in application field, because of the large difference in construction standards and functions.

\section{Conclusion}

There are different types of model in the process of intelligent community building and these models are different in operation. Their advantages can solve the problems in the intelligent community building. The intelligent community building is in the developing stage, if the different building models and developing approaches can be united to some degree, the relations between different levels can be made clear; the coordinated scheme of intelligent community building can be formed. The scheme is chartered by the municipal planning, co-ordination district, neighborhood and community specific implementation and the wide participation of residents. The scheme can make a great development for the intelligent community [11].

\section{References}

[1] H. Zhu and D.F. Ma: Manager' Journal, (2015) No.12, p.149 (In Chinese)

[2] L.Q.Wang, S.J.He and X.H.Yuan: Zhu and D.F. Ma Research and Exploration in Laboratory, vol.33 (2014) No.1, p.123-127 (In Chinese)

[3] Y.X.Gong, X.Z.Wu and Q.S.Zheng.: Zhu and D.F. Computer Engineering and Design, vol.35 (2014) No.1, p.344-349 (In Chinese)

[4] Y. Shen Y.W Chai and X.J. Ma: Modern Urban Research, vol.29 (2014) No.10, p.13-17 (In Chinese)

[5] C.Z. Zheng, D.D. Gu and G.Y. Gao: Science and Technology Management Research, vol.33 (2013) No.9, p.53-56 (In Chinese) 
[6] J.C. Wang, B. Gao and Y.X. Lei: Journal of Socialist Theory Guide, (2012) No.11, p.13-15 (In Chinese)

[7] S.W. Wu, Z. F. Zhu. and H. Y. Wu: Urban Development Studies, vol.21 (2013) No.6, p.145-147 (In Chinese)

[8] G.Q. LI, and Y. Li: Journal of Guangzhou University(Social Science Edition), vol.14 (2015) No.12, p.67-71 (In Chinese)

[9] X.F. Wang and X.R. Chen: intelligent community(Publishing House Of Electronics Industry, China 2015)

[10] Y. Lu: Management Observer, (2015) No.7, p.185-187 (In Chinese)

[11] Y. Zhou: Study on the Construction of Jingan District Shimen Two Road Smart Community in Shanghai (MS., Dalian Maritime University, China2015), p.33-p.45 